\title{
ESTUDO DA SUBSTITUIÇÃO PARCIAL DE PÓ DE PEDRA POR PET EM CONCRETO PARA FABRICAÇÃO DE PISOS INTERTRAVADOS*
}

\author{
Jaqueline de Assis Oliveira ${ }^{1}$ \\ Alisson Alves ${ }^{2}$ \\ Amanda Martins FernaQdes ${ }^{3}$ \\ Ricardo Luiz Perez Teixeira ${ }^{4}$ \\ Leonardo Lúcio de Araújo Gouveia ${ }^{5}$
}

\section{Resumo}

Este trabalho propõe avaliar a atuação do polietileno tereftalato (PET) como um agregado substituto na fabricação de concreto para pavers, pavimento intertravado com peças de concreto, a fim de minimizar os efeitos colaterais da construção civil. PET triturado substituiu o agregado natural, pó de pedra, nas porcentagens de $10 \%$, $15 \%$ e $20 \%$ em massa. Os testes mecânicos de resistência à compressão realizado aos 28 dias mostraram que os corpos de prova moldados a partir dos traços substituídos apresentaram significativa melhora da resistência à compressão, que a substituição parcial de $10 \%$ em massa de PET atende ao recomendado pela NBR 9781 (2013) para concreto para pavimentação e que todos os concretos produzidos atendem a resistência mínima a compressão de $20 \mathrm{MPa}$, recomendado pela NBR 6118 (2003) para concreto estrutural.

Palavras-chave:PET; Pavers; Resistência à compressão; Construção civil.

\section{STUDY OF PARTIAL REPLACEMENT OF STONE POWDER FOR PET TO PAVERS MANUFACTURE}

\begin{abstract}
This work proposes the performance evaluation of polyethylene terephthalate (PET) as an aggregate replacement in the concrete manufacturing for interlocking concrete pavements, in order to minimize the side effects of the construction industry. Crushed PET replaced the natural aggregate, stone dust, in percentages of $10 \%, 15 \%$ and $20 \%$ by mass. The compressive strength test performed after 28 days showed that the specimens molded from the replaced mix showed significant improvement in compared to specimens molded by the reference mix PET in percentages of $10 \%$ by mass meets the minimum strength of $35 \mathrm{MPa}$ recommended by NBR 9781 (2013) for pavers and all concretes produced meets the minimum strength of $20 \mathrm{MPa}$ recommended by NBR 6118 (2003) for structural concrete.
\end{abstract}

Keywords: PET; Pavers; Compressive strength; Civil construction.

1 Graduanda em Engenharia Civil, Universidade do Estado de Minas Gerais- FaEnge,, João Monlevade, Minas Gerais, Brasil, jaquelineassisoliveira@gmail.com

2 Graduando em Engenharia Civil, Universidade do Estado de Minas Gerais- FaEnge,, João Monlevade, Minas Gerais, Brasil,alissonalves-nc@hotmail.com

3 Graduanda em Engenharia de Materiais, Universidade Federal de Itajubá- Campus Itabira, Itabira, Minas Gerais, Brasil, martinsfernandes amanda@hotmail.com

4 Membro da ABM; Eng. Químico, Dr. em Engenharia Metalúrgica e de Materiais pela UFRJ, docente e coordenador de curso,curso de Engenharia de Materiais, Universidade Federal de ItajubáCampus de Itabira, Itabira, Minas Gerais Brasil, ricardo.luiz@unifei.edu.br

5 Geógrafo, Me. em geografia, docente, departamento de Engenharia Metalúrgica, Universidade Estadual de Minas Gerais- FaEnge, João Monlevade, Minas Gerais, Brasil, gouveialeo@yahoo.com.br 


\section{INTRODUÇÃO}

Há milhares de anos, extraem-se recursos do planeta em virtude das necessidades e luxos de grande parte da população. $O$ ato de modificar o meio que se vive é intrínseco à natureza humana e garante sobreviver em condições adversas, além de permitir que se estabeleça uma sociedade denominada tecnológica. No entanto, inicialmente o homem ignorou a finitude dos recursos naturais e as consequências de suas ações predatórias sobre a natureza.

Por isso, é imprescindível criar uma diversidade de alternativas que equilibrem aspectos tecnológicos, econômicos e ambientais.

Atualmente, reduzir-se a quantidade de resíduos sólidos gerados pelas indústrias é uma grande preocupação dos países em desenvolvimento como o Brasil. Sabe-se que a indústria da construção civil é responsável pelo consumo de aproximadamente $40 \%$ dos recursos naturais extraídos sendo, portanto, o setor responsável pela maior parte de resíduos gerados pela sociedade [1].

A temática ambiental vem cada dia mais se tornando pauta indispensável na esfera mundial. Nesse contexto, tecnologias e materiais que causam um menor impacto ambiental vêm sendo desenvolvidas para minimizar os efeitos colaterais da construção civil.

Tendo em vista os materiais potencialmente recicláveis no contexto urbano, o reciclado de polietileno tereftalato (PET) já vem sendo utilizado em diversos segmentos industriais, porém ainda pouco empregado na construção civil, como revela um censo realizado pela Associação Brasileira da Indústria do PET (ABIPET) em 2011[2].

Nessa perspectiva, o presente trabalho avaliará a eficiência do Poli (tereftalato de etileno), PET, como um agregado substituto na fabricação de pavers, pavimento intertravado com peças de concreto, largamente utilizado para a construção de pavimentos flexíveis urbanos, devido a características como durabilidade e facilidade de manejo, além de dispensar equipamentos especiais e de grande porte, o que leva a um menor tempo de construção e a consequente liberação ao tráfego imediato [3, 4].

Diante do exposto, a pesquisa então se justifica pela importância de se aliar construção civil à sustentabilidade, em busca de novos métodos e insumos recicláveis, sem que se percam características importantes à qualidade destes artefatos e reduzindo custos.

\section{MATERIAIS E MÉTODOS}

Para a aplicação deste estudo foram utilizados os materiais convencionais empregados na fabricação de concreto (cimento CP V- ARI, areia média, pó de pedra, brita 0 , água e aditivo).

Inicialmente amostras dos insumos coletados foram submetidas aos testes de granulometria, utilizando-se a norma ABNT NBR NM 248 (2003), Agregados Determinação da composição granulométrica. Posteriormente estas serão sujeitas à análise de massa específica e massa unitária conforme ABNT NBR NM 52 (2009) e ABNT NBR NM 45 (2006) respectivamente.

Após as análises de caracterização física de todos os insumos, conforme apresentado os resultados na tabela 1 , iniciou-se a confecção do concreto. O primeiro passo para se produzir o concreto em teste, será a determinação de sua formulação referencial, isto é, seu traço padrão referencial. 
Após a definição do traço referencial, admitiu-se novas dosagens com a substituição em massa do agregado natural, pó de pedra, por PET triturado nas porcentagens de $10 \%, 15 \%$ e $20 \%$ em massa.

A partir da fixação das dosagens, iniciou-se a confecção dos pavers. Os insumos foram misturados em betoneira, moldados em formas plásticas, e posteriormente adensados em mesa vibratória. Foram fabricadas 8 peças nas dimensões $10 \mathrm{~cm} \times 20 \mathrm{~cm} \times 8 \mathrm{~cm}$ por dosagem experimental. Após 24 horas os pavers foram desformados e submetidos a cura por aspersão de água.

Após 28 dias as peças foram submetidas ao teste de resistência à compressão.

\section{RESULTADOS E DISCUSSÃO}

\subsection{Caracterização física dos insumos}

Tabela 1. Caracterização física dos insumos

\begin{tabular}{lcccc}
\hline Amostra & $\begin{array}{c}\text { Diâmetro } \\
\text { Máx. (mm) }\end{array}$ & $\begin{array}{c}\text { Módulo de } \\
\text { Finura }\end{array}$ & $\begin{array}{c}\text { Massa } \\
\text { Específica } \\
\left(\mathbf{g} / \mathbf{c m}^{\mathbf{3}} \mathbf{)}\right.\end{array}$ & $\begin{array}{c}\text { Massa } \\
\text { Unitária } \\
\left(\mathbf{g} / \mathbf{c m}^{3} \mathbf{)}\right.\end{array}$ \\
Areia & 4,8 & 2,66 & 2,67 & 1,55 \\
Brita 0 & 12,5 & 6,38 & 2,62 & 1,48 \\
Pó de Pedra & 4,8 & 1,37 & 2,64 & 1,58 \\
PET & 6,3 & 5,5 & 1,36 & 0,28 \\
\hline
\end{tabular}

\subsection{Traço referência e traço substituído}

O traço referência adotado para a fabricação dos pavers amostrados foi um traço comercial já utilizado por uma indústria de pré-moldados localizada em João Monlevade- MG.

Para o traço referência os materiais utilizados foram o cimento CP-V ARI, a brita 0 , água, areia média e o aditivo MC Powerflow plastificante.

$\mathrm{Na}$ tabela 2, a seguir, encontra-se o traço em massa utilizado para a fabricação dos pavers referência, sendo que a relação água/cimento utilizada foi de $a / c=0,5$.

Tabela 2. Traço referência em massa

\begin{tabular}{cccccccc}
\hline Traços & $\begin{array}{c}\text { Cimento } \\
(\mathbf{K g})\end{array}$ & $\begin{array}{c}\text { Areia } \\
\mathbf{( K g})\end{array}$ & $\begin{array}{c}\text { Pó de } \\
\text { Pedra } \mathbf{( K g})\end{array}$ & $\begin{array}{c}\text { Brita 0 } \\
(\mathbf{K g})\end{array}$ & $\begin{array}{c}\text { PET } \\
\mathbf{( K g )}\end{array}$ & $\begin{array}{c}\text { Água } \\
(\mathbf{K g})\end{array}$ & $\begin{array}{c}\text { Aditivo } \\
(\mathbf{m l})\end{array}$ \\
\hline TR & 1 & 2,75 & 0,5 & 1,75 & 0 & 0,5 & 10 \\
\hline
\end{tabular}

Já a tabela 3 apresenta os três traços substituídos, com redução em massa de pó de pedra e adição de PET.

Tabela 3. Traços substituídos em massa

\begin{tabular}{cccccccc}
\hline Traços & $\begin{array}{c}\text { Cimento } \\
(\mathbf{K g})\end{array}$ & $\begin{array}{c}\text { Areia } \\
\mathbf{( K g )}\end{array}$ & $\begin{array}{c}\text { Pó de Pedra } \\
\mathbf{( K g )}\end{array}$ & $\begin{array}{c}\text { Brita 0 } \\
(\mathbf{K g})\end{array}$ & $\begin{array}{c}\text { PET } \\
(\mathbf{K g})\end{array}$ & $\begin{array}{c}\text { Água } \\
(\mathbf{K g})\end{array}$ & $\begin{array}{c}\text { Aditivo } \\
(\mathbf{m l})\end{array}$ \\
\hline $\mathrm{T} 10 \%$ & 1 & 2,75 & 0,45 & 1,75 & 0,05 & 0,5 & 10 \\
$\mathrm{~T} 15 \%$ & 1 & 2,75 & 0,425 & 1,75 & 0,075 & 0,5 & 10 \\
$\mathbf{T} 20 \%$ & 1 & 2,75 & 0,4 & 1,75 & 0,1 & 0,5 & 10 \\
\hline
\end{tabular}




\subsection{Análise da resistência à compressão}

Os ensaios mecânicos de resistência à compressão realizados nos corpos de prova nas idades de 28 dias permitiram plotar um gráfico comparando a resistência do traço referência e do traço substituído pó de pedra, por PET triturado nas respectivas porcentagens de $10 \%$ em massa, $15 \%$ em massa e $20 \%$ em massa, conforme mostra a figura 1.

$\mathrm{Na}$ figura 1 as barras azuis representam os corpos de prova com traço referência na idade de 28 dias, enquanto as barras vermelhas representam os corpos de prova com traço utilizando PET na idade de 28 dias. A primeira comparação ocorre entre o traço referência e a substituição com $10 \%$ em massa de PET, a segunda comparação observa-se o traço referência e a substituição com $15 \%$ em massa de PET e por fim, compara-se o traço referência com a substituição de $20 \%$ em massa de PET. Em todos os valores de resistência à compressão obtidos, deve-se considerar um desvio padrão de $\pm 0,5 \mathrm{MPa}$, proveniente do equipamento utilizado para a medição.

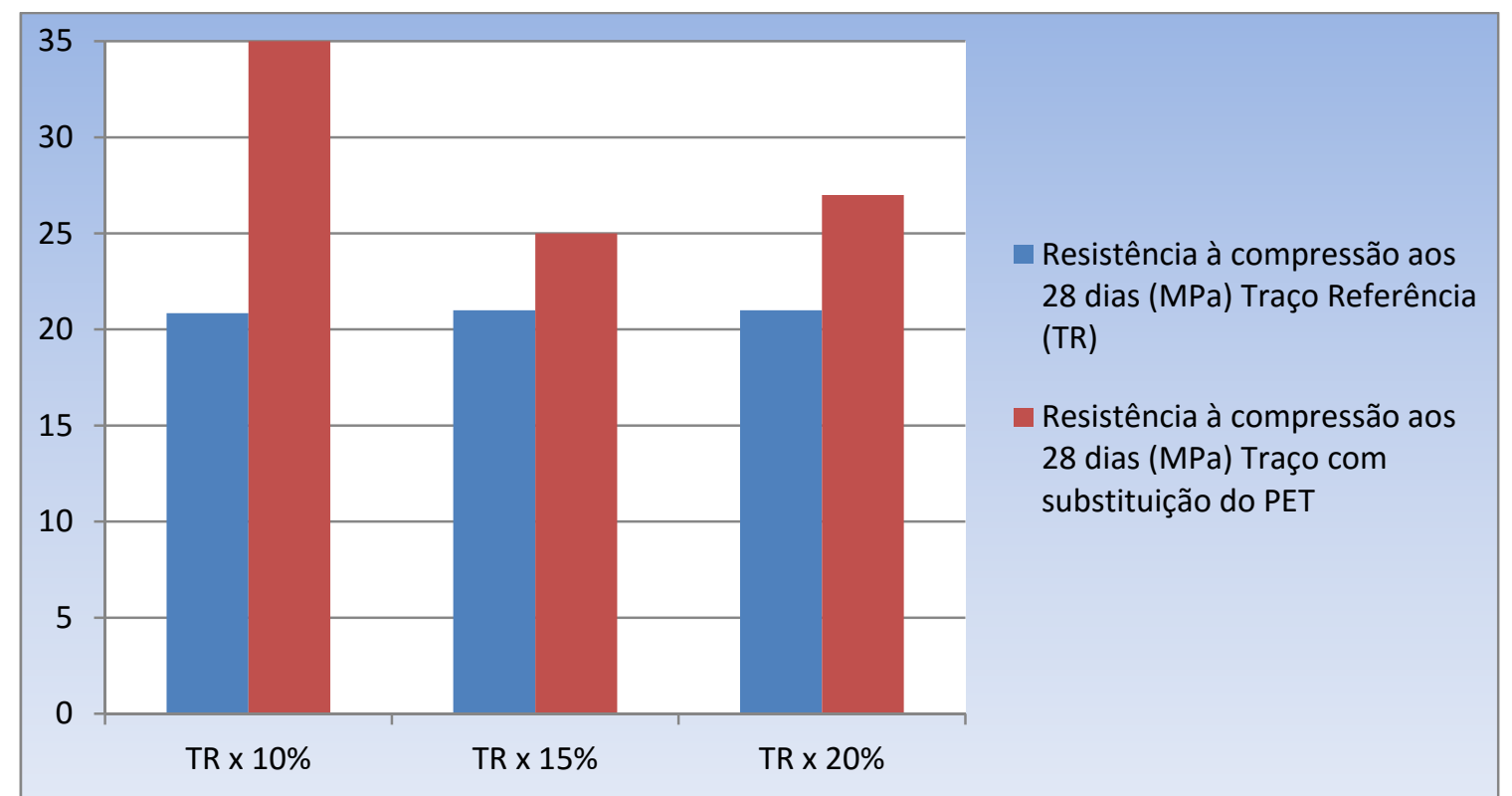

Figura 1. Gráfico da resistência à compressão do Traço Referência estudado x Traços Substituídos de PET em massa.

Analisando o gráfico da figura 1 é possível constatar que a adição em massa de PET triturado pós consumo com a granulometria estudada promove um aumento na resistência à compressão em todas substituições estudadas. $\mathrm{Na}$ idade de 28 dias a comparação entre o corpo de prova referência e o corpo de prova substituído por $10 \%$ em massa de PET fornece um aumento de aproximadamente $67 \%$ na resistência à compressão das peças, enquanto que aos 28 dias, porém com a substituição de $15 \%$ esse aumento é de aproximadamente $19 \%$ e quando analisado a substituição de $20 \%$ a resistência é aumentada em $28 \%$. Aos 28 dias, a adição de $10 \%$ em massa de PET atendeu a exigência de resistência mínima $35 \mathrm{MPa}$, conforme a ABNT NBR 9781 (2013).

\section{CONCLUSÃO}

A análise granulométrica do PET e os testes de resistência à compressão realizados nos corpos de prova moldados a partir do traço referência e dos traços substituídos 
permitem concluir que a adição de somente $10 \%$ em massa de PET com a granulometria estudada já é capaz de aumentar a resistência à compressão aos 28 dias de idade, fazendo com que o concreto possa ser utilizado em pavers destinados ao tráfego de pedestres, veículos leves e veículos comerciais de linha, que possuem exigência de resistência mínima 35 MPa, conforme a ABNT NBR 9781 (2013). Pelos resultados apresentados também, todas as dosagens com a substituição em massa do agregado natural por PET triturado nas porcentagens de $10 \%, 15 \%$ e $20 \%$ em massa atenderam a resistência mínima a compressão de $20 \mathrm{MPa}$, recomendado pela ABNT NBR 6118 (2003) para fins estruturais.

Portanto, a adição de PET triturado pós-consumo ao concreto destinado à pavers, revela-se bastante promissor na dosagem de $10 \%$ em massa em substituição ao agregado natural, pois melhora as propriedades mecânicas do concreto, atende a norma ABNT NBR 9781 (2013) e, ao mesmo tempo, propicia uma redução na quantidade de resíduo PET no meio ambiente.

\section{Agradecimentos}

Os autores gostariam de agradecer à Fundação de Amparo à Pesquisa do Estado de Minas Gerais - FAPEMIG, à Universidade do Estado de Minas Gerais (UEMG) Campus João Monlevade FAENGE, ao grupo de pesquisa MATCIME da UNIFEICampus de Itabira, à empresa Minas Pré-Moldados e a MC- Bauchemie.

\section{REFERÊNCIAS}

1 SANTOS, J.R. Betão com agregados grossos reciclados de betão. Concreto\& Construções. 2005; 37:10-14.

2 ASSOCIAÇÃO BRASILEIRA DA INDÚSTRIA DO PET (ABIPET). Nono Censo da Reciclagem do PET no Brasil. 2013 [Acesso em: 02/10/2015]. Disponível em: <http://www.abipet.org.br/index.html?method=mostrarDownloads\&categoria.id=3>.

3 ASSOCIAÇÃO BRASILEIRA DE CIMENTO PORTLAND (ABCP). Pavimento Intertravado alia durabilidade e estética. 2012 [Acesso em: 02/10/2015]. Disponível em: $<$ http://www.abcp.org.br/conteudo/imprensa/pavimento-intertravado-alia-durabilidade-eestetica>.

4 SAIKIA, N.; BRITO, J. Waste polyethylene terephthalate as an aggregate in concrete.Mat. Res. [online]. 2013. 16: 341-350 [Acesso em: 11/04/2016]. Disponível em: <http://www.scielo.br/scielo.php?script=sci_arttext\&pid=S1516$14392013000200011 \&$ Ing=en\&nrm=iso>.

5 ABNT - Associação Brasileira de Normas Técnicas. Peças de concreto para Pavimentação - Especificação e métodos de ensaio. NBR - 9781. Rio de Janeiro, 2013. 